\title{
MUTATIONS OF THE P53 TUMOR SUPPRESSOR GENE AS CLONAL MARKER FOR MULTIPLE PRIMARY LUNG CANCERS
}

Tetsuya Mitsudomi, $\mathrm{MD}^{\mathrm{a}}$

Yasushi Yatabe, MD $^{\mathrm{b}}$

Takashi Koshikawa, MD $^{\mathrm{b}}$

Shunnzo Hatooka, $\mathrm{MD}^{\mathrm{a}}$

Masayuki Shinoda, $\mathrm{MD}^{\mathrm{a}}$

Motokazu Suyama, MD

Takahiko Sugiura, $\mathrm{MD}^{\mathrm{c}}$

Makoto Ogawa, $\mathrm{MD}^{\mathrm{c}}$

Takashi Takahashi, MD $^{\mathrm{d}}$

\begin{abstract}
Objectives: Second primary lung cancers are prevalent after treatment for initial lung cancer, and the lung is also one of the most frequent sites for recurrence after removal of early-stage lung cancer. The objective of the present study is to clarify the clonal origin of the second tumor with the p53 gene mutation used as a clonal marker. Methods: Of 794 consecutive patients who underwent pulmonary resection for primary lung cancer from 1980 to 1993,22 required second pulmonary resection during the follow-up period, with a median interval of 38 months. We examined 16 of these patients for mutations of the p53 gene occurring in exons 5 through 8 by the polymerase chain reaction/single strand conformation polymorphism method. Differential diagnosis was also made on a morphologic basis, considering the degree of cellular differentiation and cytologic subtypes. Results: Nine of the 16 patients analyzed had at least one p53 mutation in their tumors. We were thus able to make molecular diagnoses for these patients. The mutational status of the $\mathbf{p 5 3}$ gene was discordant in all nine patients, suggesting a different clonal origin despite the fact that six of them had almost identical histologic features. Conclusions: Analysis of p53 gene mutations was thus useful in distinguishing second primary lung cancers from recurrent tumors. The observed heterogeneity of $\mathrm{p53}$ status was also in line with the "field cancerization" concept. (J Thorac Cardiovase Surg 1997;114:354-60)
\end{abstract}

The he incidence of lung cancer occurring as a second neoplasm is high after curative pulmonary resection for early-stage lung cancer. For example, Pairolero, ${ }^{1}$ Martini, ${ }^{2}$ and their associates reported $10 \%$ and $12 \%$ incidences of second primary lung cancers, respectively, in their groups of 346 and 598 patients with resected stage I non-small-cell lung cancers. ${ }^{1,2}$ On the other hand, the lung, like the brain, is a frequent site of hematogenous recurrence after po-

From the Departments of Thoracic Surgery, ${ }^{\text {a }}$ Pathology and Clinical Laboratories, ${ }^{\mathrm{b}}$ and Internal Medicine, ${ }^{\mathrm{c}}$ Aichi Cancer Center Hospital, and Laboratory of Ultrastructure Research, ${ }^{\mathrm{d}}$ Aichi Cancer Center Research Institute, Nagoya, Japan.

This work was in part supported by the Bristol-Meyers Squibb Biomedical Research Grant Program and a grant from the Aichi Cancer Research Foundation.

Received for publication March 11, 1997; revisions requested April 22, 1997; revisions received May 12, 1997; accepted for publication May 14, 1997.

Address for reprints: Tetsuya Mitsudomi, MD, Chief, Department of Thoracic Surgery, Aichi Cancer Center Hospital, 1-1 Kanokoden, Chikusa-ku, Nagoya 464, Japan.

Copyright (C 1997 by Mosby-Year Book, Inc.

$0022-5223 / 97 \$ 5.00+0 \quad \mathbf{1 2 / 1 / 8 3 2 3 2}$ tentially curative resection of lung cancer. ${ }^{2-5}$ Consequently, it is sometimes difficult to distinguish multiple primary tumors from recurrent tumors. The fact that the histologic features of a second primary lung cancer tend to repeat those of the initial lesion further compounds this problem. . $^{6}$

Martini and Melamed $^{6}$ in 1975 proposed the criteria that are currently most widely used for distinguishing multiple primary tumors from recurrent tumors. Essentially, a second tumor is considered as an independent primary tumor when the histologic characteristics are different, or even when the histologic features are the same, if the free interval was more than 2 years or if the first tumor was resected at a relatively early stage. However, no definite theoretically sound background for these criteria has been established.

Several major genetic approaches for determination of the clonality of human tumors are based on $\mathrm{X}$-chromosome inactivation analysis in female patients, immunoglobulin or $\mathrm{T}$-cell receptor gene analysis for lymphoid tumors, and the occurrence of somatic mutations of oncogenes or tumor suppressor genes. ${ }^{9}$ Analysis of mutations occurring in the 
p53 tumor suppressor genes is considered particularly useful. With regard to lung cancers, the p53 tumor suppressor gene has been found so far to be the most frequently mutated gene, with mutations present in 50\% of non-small-cell and in almost all small-cell lung cancers. ${ }^{10}$ The majority of mutations are widely distributed, involving various codons in exons 5 through $8,{ }^{11-13}$ in clear contrast to the exclusive occurrence of ras gene mutations at codons 12,13 , or $61 .^{14}$ Therefore it is not likely that two independent tumors would have the same p53 mutation by chance alone. Another advantage is that mutations of the p53 gene occur relatively early in the development of lung cancer, especially in those of squamous cell type, ${ }^{15}$ and because they have a role in maintenance of the malignant phenotype, ${ }^{16}$ once acquired they are well preserved during progression or metastatic spread. ${ }^{17}$

In this study, we therefore examined 16 patients with metachronous lung tumors to determine the applicability of p53 gene mutations for differentiation of second primary tumors in the lung. The molecular diagnostic results were also compared with diagnoses made on the morphologic features and with the clinical criteria proposed by Martini and Melamed. ${ }^{6}$

\section{Patients and methods}

Patients. During a 14-year-period from 1980 to 1993 , 794 patients with primary lung cancers underwent pulmonary resection at the Department of Thoracic Surgery, Aichi Cancer Center Hospital. Of these, 22 (3\%) required a second pulmonary resection by the end of 1995 for suspected second primary or solitary pulmonary recurrent tumors. In the present study, we analyzed 16 of these patients (32 tumors) for whom archival materials were available. The patients included 10 men and six women. Their median age at the time of the first operation was 55 years (range 39 to 77 years). The histologic features of the two tumors were the same in 12 patients and different in the remaining four. The median interval between the two operations was 38 months (range 7 to 89 months). Following the American Joint Committee staging system published in $1986,{ }^{18} 14$ tumors at the first operation were classified as stage I and the remaining two were classified as stage II.

Morphologic diagnosis of lung cancer. The resected tumors were routinely fixed in $10 \%$ formaldehyde and embedded in paraffin. Sections cut at $3 \mu \mathrm{m}$ were stained with hematoxylin and eosin for histologic examination. Differential diagnosis was based on the degree of cellular differentiation and the cytologic subtypes in the adenocarcinoma cases, essentially as proposed by Shimosato. ${ }^{19} \mathrm{We}$ combined the Clara cell subtype with the type II pneumocyte subtype to give a single group, referred to as adenocarcinomas with peripheral airway cell morphology (PAC), because of the frequent coexistence of the two cell types. Consequently, adenocarcinomas were subclassified into PAC, bronchial surface epithelial cell $(\mathrm{BrS})$, bronchial gland (BrG), goblet cell (Gob), and poorly differentiated (P/D) adenocarcinoma categories. For comparison with the World Health Organization classification, the PAC includes most bronchioloalveolar carcinomas and a large proportion of papillary adenocarcinomas, $\mathrm{BrG}$ includes the majority of acinar adenocarcinomas, BrS encompasses the remainder of the papillary and acinar adenocarcinomas, and Gob constitutes a subcategory of bronchioloalveolar carcinomas. ${ }^{20}$ The second tumor was diagnosed as a second primary when the histologic type or cytologic subtype was different from that of the first lesion.

Extraction of deoxyribonucleic acid from formalinfixed paraffin-embedded materials. Single $8 \mu \mathrm{m}$ thick paraffin sections were used for genomic deoxyribonucleic acid (DNA) extraction. After deparaffinization with xylene, they were lightly stained with hematoxylin, and tumor cells were then microdissected out by means of a needle with a syringe under a dissecting microscope. The dissected tissue was digested in $50 \mu \mathrm{l}$ of buffer consisting of tromethamine, $20 \mathrm{mmol} / \mathrm{L}(\mathrm{pH} 8.0)$, ethylenediaminetetraacetic acid, $1 \mathrm{mmol} / \mathrm{L}, 0.5 \%$ Tween 20 , and proteinase $\mathrm{K}, 200 \mu \mathrm{g} / \mathrm{ml}$, for 24 to 48 hours at $37^{\circ} \mathrm{C}$ and then incubated for 15 minutes at $95^{\circ} \mathrm{C}$ to inactivate the proteinase K, essentially as described by Sugio and coworkers. ${ }^{21}$ Solution in aliquots of $1 \mu \mathrm{l}$ was used for each experiment.

Polymerase chain reaction/single strand conformation polymorphism analysis. Mutations of the p53 gene occurring in exons 5 through 8 were screened by polymerase chain reaction/single strand conformation polymorphism (PCR/SSCP) analysis. ${ }^{22}$ However, because of the limited quality of DNA extracted from formalin-fixed specimens, a hemi-nested PCR strategy was used to give PCR products sized less than 200 base pairs. Exons 5 and 8 were each divided into two overlapping fragments. Sequences for the primers applied are available on request. Onemicroliter aliquots of the first PCR products were reamplified with a pair of external primers in a volume of $10 \mu \mathrm{l}$ including $0.5 \mu \mathrm{l}$ of $\left[\alpha^{-32} \mathrm{P}\right]$ deoxycytidine triphosphate (3000 Ci $/ \mathrm{mmol}, 10 \mathrm{mCi} / \mathrm{ml}$, Amersham, Arlington, Ill.). The PCR products were diluted with loading buffer, heat degenerated, loaded onto nondenaturing $6 \%$ polyacrylamide gels, and electrophoresed at $25 \mathrm{~W}$ for 5 hours or at $40 \mathrm{~W}$ for 2.5 hours in a cold room $\left(4^{\circ} \mathrm{C}\right)$ with or without a cooling fan, essentially as described elsewhere. ${ }^{11}$ After electrophoresis, the gels were dried and exposed to $\mathrm{x}$-ray films at $-70^{\circ} \mathrm{C}$.

\section{Results}

Clinical diagnosis using Martini and Melamed's criteria and morphologic diagnosis considering cytologic subtypes. Following the criteria proposed by Martini and Melamed, ${ }^{6}$ which are currently the most widely used for distinguishing multiple primary tumors from recurrent tumors, multiple primary tumors were diagnosed in all 16 patients (Table I, column 4). 
Table I. Patient characteristics and summary of the results

\begin{tabular}{|c|c|c|c|c|c|c|c|c|c|}
\hline \multirow[b]{2}{*}{ Case } & \multirow[b]{2}{*}{ Age, sex } & \multirow{2}{*}{$\begin{array}{c}\text { Interval } \\
\text { (mo) }\end{array}$} & \multirow{2}{*}{$\begin{array}{c}\text { Clinical } \\
\text { diagnosis * }\end{array}$} & \multicolumn{2}{|c|}{ Histologic subtypef } & \multirow{2}{*}{$\begin{array}{c}\text { Morphologic } \\
\text { diagnosist }\end{array}$} & \multicolumn{2}{|c|}{ p53 mutation } & \multirow{2}{*}{$\begin{array}{l}\text { Molecular } \\
\text { diagnosis }\end{array}$} \\
\hline & & & & First tumor & Second tumor & & First tumor & Second tumor & \\
\hline 1 & $56, \mathrm{M}$ & 8 & M & $\mathrm{AD} P A C$ & $\mathrm{AD} P / \mathrm{D}$ & $\mathrm{M}$ & - & Ex 5 & M§ \\
\hline 2 & $62, \mathrm{~F}$ & 37 & $\mathbf{M}$ & $\mathrm{AD} P A C$ & $\mathrm{AD} P A C$ & $\mathrm{R}$ & - & - & $?$ \\
\hline 3 & $71, \mathrm{M}$ & 73 & $\mathrm{M}$ & LA & $\mathrm{AD} P / \mathrm{D}$ & $\mathrm{M}$ & - & - & $?$ \\
\hline 4 & $77, \mathrm{~F}$ & 39 & $\mathrm{M}$ & $\mathrm{AD}$ PAC & $\mathrm{AD}$ PAC & $\mathrm{R}$ & Ex 6 & - & M \\
\hline 5 & $50, \mathrm{M}$ & 30 & $\mathrm{M}$ & SQ W/D & $\mathrm{AD} B \mathrm{BrG}$ & M & Ex 6 & Ex 8 & M \\
\hline 6 & $49, \mathrm{M}$ & 14 & M & $\mathrm{AD} \mathrm{BrS}$ & $\mathrm{AD} \mathrm{BrS}$ & $\mathrm{R}$ & - & - & $?$ \\
\hline 7 & $53, \mathrm{~F}$ & 89 & M & $\mathrm{AD} P A C$ & $\mathrm{AD} P A C$ & $\mathrm{R}$ & Ex 6 & - & M \\
\hline 8 & $43, F$ & 26 & M & $\mathrm{AD} P A C$ & AD PAC & $\mathrm{R}$ & - & - & $?$ \\
\hline 9 & $40, \mathrm{~F}$ & 44 & M & $\mathrm{AD} \mathrm{BrS}$ & $\mathrm{AD} \mathrm{BrS}$ & $\mathrm{R}$ & - & - & $?$ \\
\hline 10 & $40, \mathrm{M}$ & 32 & M & $\mathrm{AD} P / \mathrm{D}$ & $\mathrm{SQ} \mathrm{M} / \mathrm{D}$ & M & - & - & $?$ \\
\hline 11 & $57, \mathrm{M}$ & 43 & M & $\mathrm{SQ} \mathrm{M} / \mathrm{D}$ & $\mathrm{SQ} \mathrm{M} / \mathrm{D}$ & $\mathrm{R}$ & - & Ex 6 & $\mathrm{M} \S$ \\
\hline 12 & $58, F$ & 57 & M & $\mathrm{AD}$ Gob & $\mathrm{AD}$ Gob & $\mathrm{R}$ & - & - & $?$ \\
\hline 13 & $53, \mathrm{M}$ & 7 & M & $\mathrm{AD} B r G$ & $\mathrm{AD} \mathrm{BrG}$ & $\mathrm{R}$ & Ex 7 & - & $\mathrm{M}$ \\
\hline 14 & $39, \mathrm{M}$ & 44 & $\mathrm{M}$ & $A D P A C$ & $\mathrm{AD} P A C$ & $\mathrm{R}$ & - & Ex 6 & $\mathrm{M} \S$ \\
\hline 15 & $58, \mathrm{M}$ & 66 & $\mathrm{M}$ & $\mathrm{SQ} \mathrm{M} / \mathrm{D}$ & $\mathrm{AD} \mathrm{BrS}$ & $\mathbf{M}$ & $\operatorname{Ex} 5$ & Ex $5 \ddagger$ & $\mathrm{M}$ \\
\hline 16 & $62, \mathrm{M}$ & 19 & M & $\mathrm{SQ} W / \mathrm{D}$ & $\mathrm{SQ} W / \mathrm{D}$ & $\mathrm{R}$ & Ex 5,8 & Ex $5 \$$ & $\mathrm{M}$ \\
\hline
\end{tabular}

$A D$, Adenocarcinoma; $P A C$, peripheral airway cell type; $P / D$, poorly differentiated; $L A$, large cell carcinoma; $S Q$, squamous cell carcinoma; $W / D$, well differentiated; $B r G$, bronchial gland type; $B r S$, bronchial surface type; $M / D$, moderately differentiated; Gob, goblet cell type; $M$, multiple primary lung cancer; $R$, recurrent metastatic tumor; $E x$, exon.

"Clinical diagnosis according to Martini and Melamed. ${ }^{6}$

$\left\lceil\right.$ Morphologic diagnosis was made using subclassification of adenocarcinomas proposed by Shimosato. ${ }^{19}$

$\$$ Different 553 mutation from that in the corresponding first tumor.

$\S I n$ these three cases, there was also a possibility that the second tumor is a clonal expansion of the first one (see text).

The histologic combinations of the first and the second tumors in the 16 patients were adenocarcinoma-adenocarcinoma $(n=10,63 \%)$, squamous carcinoma-adenocarcinoma $(n=2,13 \%)$, squamous carcinoma-squamous carcinoma $(n=2$, $13 \%)$, adenocarcinoma-squamous carcinoma $(n=$ $1,6 \%$ ), and large-cell carcinoma-adenocarcinoma $(n=1,6 \%)$. Hence, in 12 of 16 patients $(75 \%)$, the histologic type of the second tumor was the same as that of the first. The incidence of adenocarcinomas in these multiple cases ( 24 of 32 tumors, $75 \%$ ) was higher than that for single lung cancers in our institution $(52 \%)$.

Considering the cytologic features of the adenocarcinoma cells, 11 tumors were subclassified as PAC, five as BrS, three as BrG, two as Gob, and three as $\mathrm{P} / \mathrm{D}$. On the basis of these histopathologic and cytopathologic results, multiple primary tumors were diagnosed in one patient (case 1), in addition to the four patients for whom the major histologic type of each tumor differed. For the remaining 11 patients, the pairs of tumors belonged to the same morphologic subset even when cytologic subtyping was considered, and they were thus diagnosed as recurrences (morphologic diagnosis) (Table I, columns 5 and 6, and Fig. 1, $A, B, D$, and $E$ ).
Detection of p53 gene mutations and molecular diagnosis of clonality. SSCP analysis allowed us to perform p53 gene analyses within 24 hours once DNA was extracted. Thirteen p53 gene mutations were detected in 12 tumors. The incidence was 12 of $32(38 \%)$ in total, five of seven $(71 \%)$ in squamous cell carcinomas, and seven of $24(29 \%)$ in adenocarcinomas. None of the patients had the same p53 mutations in their pairs of tumors. Fig. $1, C$ and $F$ shows representative results.

In seven patients neither tumor harbored a p53 mutation. In three patients, the first tumor was negative for p53 mutation but the second one had a p53 mutation, as in Fig. 1, $C$ (cases 1, 11, and 14; pattern A). In another three patients, the first tumor had p53 mutation and the second one had none, as in Fig. 1, $F$ (cases 4, 7, and 13; pattern B). In the remaining three patients, both tumors had p53 mutations but they differed from each other (cases 5,15 , and 16; pattern $C$ ). These results are summarized in Fig. 2.

\section{Discussion}

Only a relatively small number of studies have been conducted concerning molecular clonal analysis of metachronous lung cancer. Noguchi, ${ }^{23}$ Yang, ${ }^{24}$ 

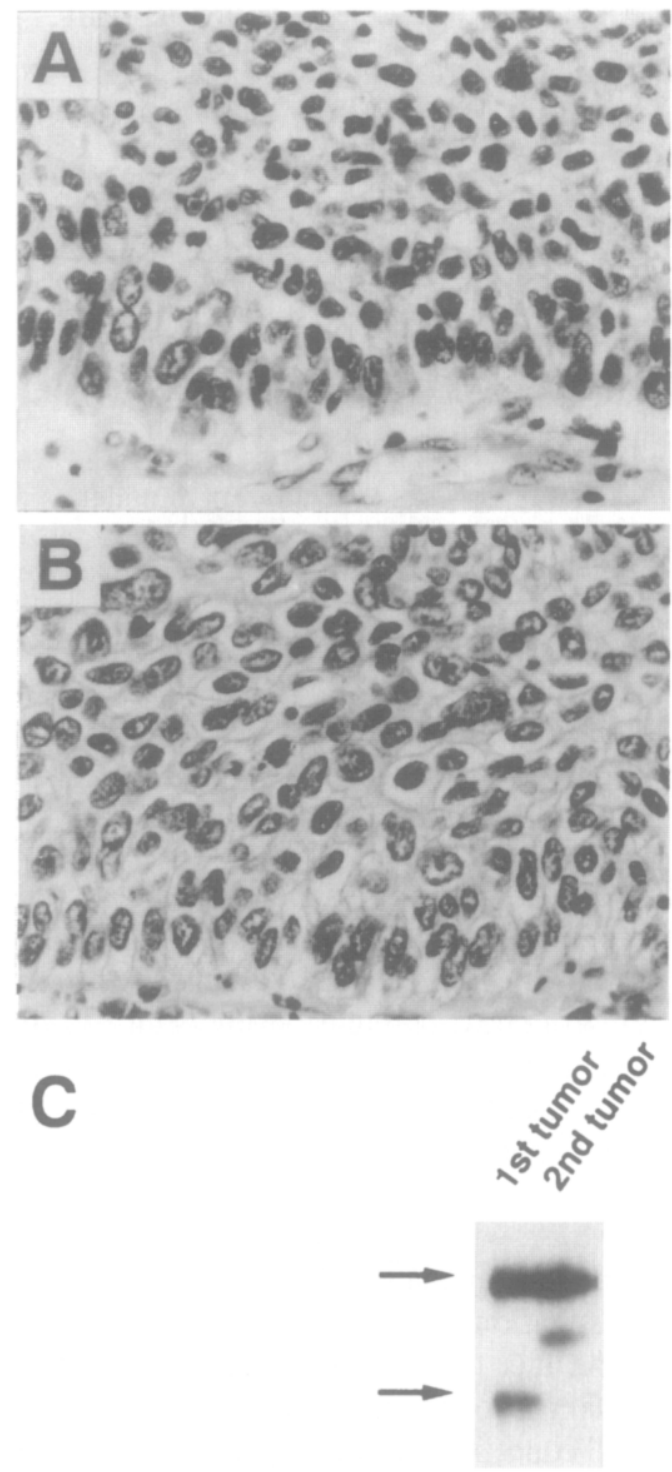
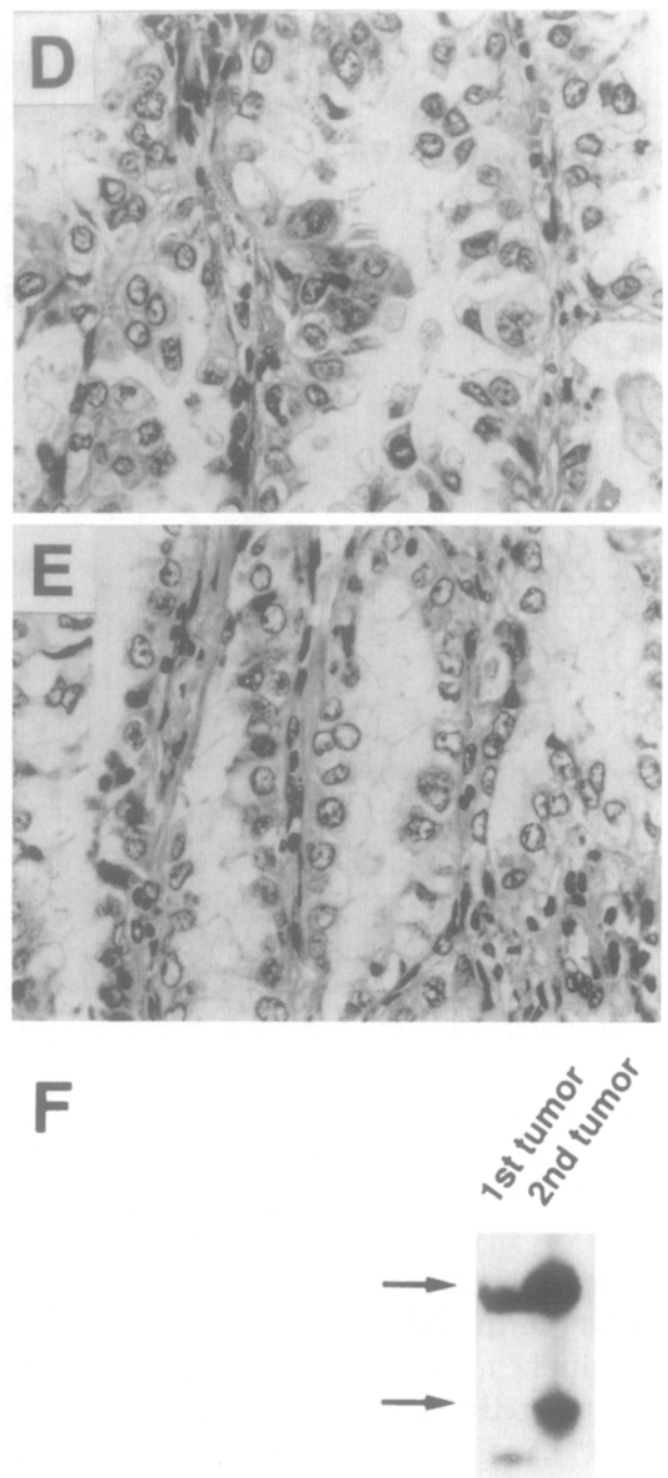

Fig. 1. Examples of comparisons of histologic features and PCR/SSCP of the p53 gene. A 57-year-old man (patient 11) underwent right upper lobectomy for squamous cell carcinoma (A). Three years 7 months later, a second squamous cell carcinoma (B) developed in the left upper lobe and was removed by lobectomy. PCR/SSCP analysis revealed a mutation in exon 6 of the p53 gene in the second tumor but not in the first (C) (pattern A, see text), although the histologic features were almost identical. A 77-year-old woman (patient 4) underwent right middle lobectomy for an adenocarcinoma of peripheral airway cell type (D). Three years 3 months later, a second adenocarcinoma of the identical morphologic type (E) developed in the left lower lobe. PCR/SSCP analysis revealed a mutation in the first tumor in exon 6 of the p53 gene, but this mutation was lost in the second lesion (F) (pattern B, see text). Arrows in panels $C$ and $F$ indicate the positions of bands for wild-type alleles.

and their colleagues examined five and four patients, respectively, among larger series of patients with head and neck tumors, but the present investigation, to our knowledge, is the first systematic molecular analysis of multiple primary lung cancers.
The detected incidences of $\mathrm{p} 53$ gene mutations, five of seven $(71 \%)$ for squamous cell carcinomas and seven of 24 (29\%) for adenocarcinoma, are in good agreement with those reported previously for single lung cancers. ${ }^{12,13,25}$ The fact that they were 


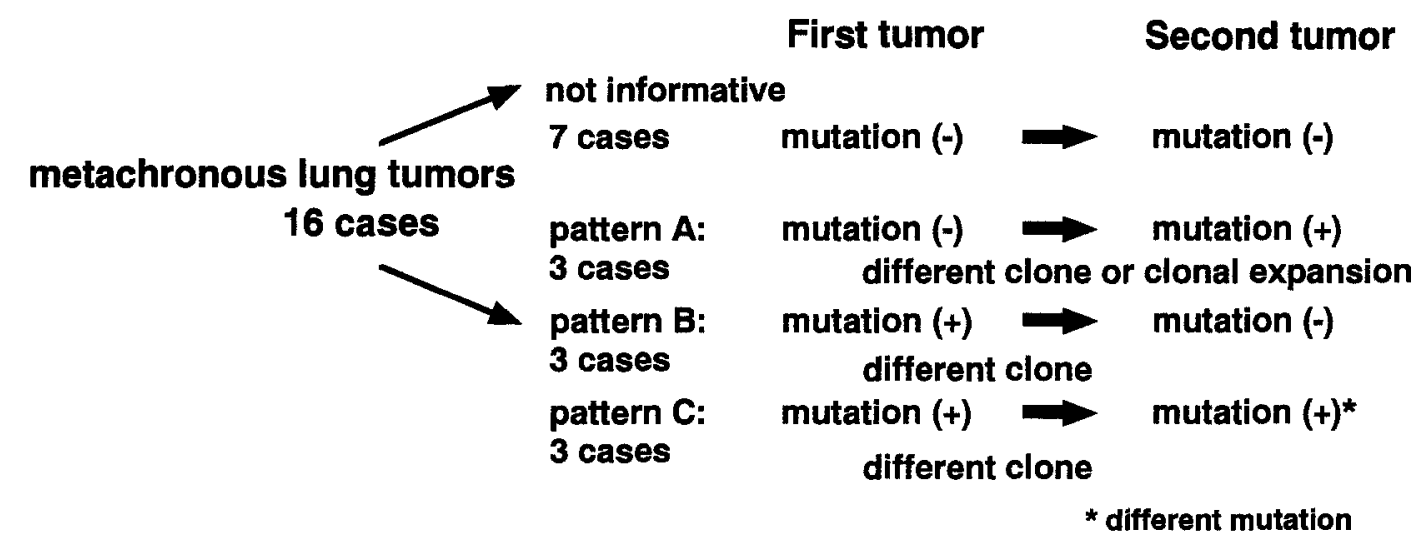

Fig. 2. Summary of $\mathrm{p} 53$ gene mutational status in metachronous lung tumors in 16 cases. For explanation of patterns $A$ to $C$, see text.

distributed equally between the first and second lesions indicates that multiplicity itself is not associated with the presence of $\mathrm{p} 53$ mutation.

Nine of 16 patients $(56 \%)$ had at least one p53 mutation in their pairs of tumors. The mutational status of the p53 gene was discordant in all nine patients, despite the fact that six of them had almost identical histologic features. Because mutations of the p53 tumor suppressor gene are thought to confer a growth advantage, ${ }^{26}$ it is not likely that they would be lost during progression or metastatic spread. In fact, Reichel and associates, ${ }^{17}$ by examining a total of 26 primary lung tumors and 60 metastases, reported that the p53 mutational status was concordant in the primary tumor and its corresponding multiple metastases in 30 of 32 tumors (94\%) that occurred in nine patients. Hence it can be concluded that the second tumor was different from the first in terms of clonal origin in three patients with pattern B (p53 mutation only in the first tumor) and in the other three patients with pattern $\mathrm{C}$ (different p53 mutation in the first and the second tumor). However, in three patients with pattern A (p53 mutation only in the second tumor), either of two conclusions are possible. One interpretation is that they are clonally different and the other is that the second tumor was in fact a clonal expansion, because of the growth advantage conferred by the p53 mutation in a minor clone that had been present in the first tumor but was not detected because of dilution effect, as has been shown in progression of astrocytoma. ${ }^{26}$ The results of the molecular diagnosis made in accordance are summarized in the last column of Table I and in Fig. 2.

It has been stated that, in treating metachronous lung cancer, the distinction between a new primary tumor and a solitary metastasis is of little importance if the new tumor is resectable. ${ }^{6}$ However, these observations are based on conventional criteria of second primary cancers. Hence a molecularly defined second primary tumor might behave differently from a molecularly defined recurrent tumor. Consequently, it might be important to distinguish them at the time of diagnosis and to select appropriate treatment. This is possible, inasmuch as we ${ }^{27}$ have previously shown feasibility of detection of p53 mutation in a small bronchial biopsy specimen. However, whether treatment policy should depend on molecular diagnosis remains an issue for future investigation.

The fact that the p53 mutational status was discordant in our study supports the "field cancerization" concept. ${ }^{28}$ In other words, carcinogenic insults affect many different susceptible cells in the respiratory tract, resulting in either synchronous or metachronous clonally distinct multiple tumors. Similarly, Noguchi and colleagues ${ }^{23}$ reported all seven p53 mutations found in four patients with metachronous lung tumors to be different. Chung and associates $^{29}$ examined 31 patients with primary head and neck tumors and corresponding second primary tumors of the upper aerodigestive tract and found 21 to have at least one p53 mutation, again with discordance in terms of presence or location in all cases. Furthermore, with field cancerization, it might be expected that a particular type of cell in the respiratory tract of a given patient (e.g., epithelial or nonepithelial) would preferentially commit to tumorigenesis by carcinogen(s) exposure proper to the patient. Hence, in more than $70 \%$ of the cases, the 
histologic type of the second tumor repeats that of the first. ${ }^{6,8}$ This was also true for the present series, even when subclassification of histologic type was considered, except in patient 1 (see Table I). However, the p53 gene mutations would not necessarily occur in the same codon in a given combination of a carcinogen and a type of cells. This may at least partially account for the discrepancy between molecular and morphologic diagnosis observed in the present study.

All but two of the first tumors were classified as stage I, and median age of the patients at the time of the first operation was 55 years, which was appreciably younger than the age (62 years) of all patients who underwent pulmonary resection for lung cancer in our institution. These young patients with earlystage lung cancer have a good chance for cure of the first primary tumor and thus have a long time for development of a second primary lesion. Alternatively, these young patients may have been heavily exposed to carcinogen(s), lung cancer thus may have developed earlier, and the patients may have been at higher risk for the development of a second primary tumor because of field effect of the carcinogen(s). Also, the possibility exists that genetic predisposition, such as a defect in the DNA repair system, ${ }^{30}$ could be playing a role.

In addition to p53 gene mutations, several other molecular tools are currently available for analysis of the clonality of lung cancers. Analysis of Xchromosomal inactivation occurring at early embryonic development is attractive ${ }^{9}$ but is applicable only to female patients. Loss of heterozygosity of certain chromosomal arms such as 3p, 5q, 9p, 11p, 13q, 17p, and $18 \mathrm{q}$ or mutations of ras genes are also possible. Although laborious, combining multiple genetic markers would certainly increase information concerning the clonal origin of tumors.

In conclusion, the present examination of metachronous lung tumors for p53 gene mutations allowed clear diagnosis of multiple primary tumors in the majority of patients despite similarities in histopathologic features.

We are grateful to Hiroji Ishida, Miyoko Mabuchi, and Yoshiroh Tokoro for their expert technical assistance.

\section{REFERENCES}

1. Pairolero PC, Williams DE, Bergstrahl EJ, Piehler JM, Bernatz PE, Payne WS. Postsurgical stage I bronchogenic carcinoma: morbid implications of recurrent disease. Ann Thorac Surg 1984;38:331-8.

2. Martini N, Bains MS, Burt ME, et al. Incidence of local recurrence and second primary tumors in resected stage I lung cancer. J Thorac Cardiovasc Surg 1995;109:120-9.

3. The Lung Cancer Study Group. Postoperative T1 N0 nonsmall cell lung cancer: squamous versus nonsquamous recurrences. J Thorac Cardiovasc Surg 1987;94:349-54.

4. Yano $T$, Yokoyama $H$, Inoue $T$, et al. The first site of recurrence after complete resection in non-small-cell carcinoma of the lung. J Thorac Cardiovasc Surg 1994;108:680-3.

5. Mitsudomi T, Nishioka K, Maruyama R, et al. Kinetic analysis of recurrence and survival after potentially curative resection of non-small cell lung cancer. J Surg Oncol 1996; 63:159-65.

6. Martini N, Melamed MR. Multiple primary lung cancers. J Thorac Cardiovasc Surg 1975;70:606-12.

7. Neugut AI, Sherr D, Robinson E, Murray T, Nieves J. Differences in histology between first and second primary lung cancer. Cancer Epidemiol Biomarkers Prev 1992;1:109-2.

8. Hida T, Ariyoshi Y, Sugiura T, Suyama M, Takahashi T, Ueda R. Synchronous lung cancer presenting with small cell carcinoma and adenocarcinoma. Chest 1993;104:1602-4.

9. Wainscoat JS, Fey MF. Assessment of clonality in human tumors: a review. Cancer Res 1990;50:1355-60.

10. Gazdar AF. The molecular and cellular basis of human lung cancer. Anticancer Res 1994;13:261-8.

11. Mitsudomi T, Steinberg S, Nau MM, et al. p53 gene mutations in non-small cell lung cancer cell lines and their correlation with the presence of ras mutations and clinical features. Oncogene 1992;7:171-80.

12. Chiba I, Takahashi T, Nau MM, et al. Mutations in the p53 gene are frequent in primary, resected non-small cell lung cancer. Oncogene 1990;5:1603-10.

13. Suzuki H, Takahashi T, Kuroishi T, Suyama M, Ariyoshi $Y$, Takahashi T. p53 mutations in non-small cell lung cancer in Japan: association between mutations and smoking. Cancer Res 1992;52:734-6.

14. Bos JL. Ras oncogenes in human cancer: a review [published erratum appeared in Cancer Res 1990 Feb 15;50:1352]. Cancer Res 1989;49:4682-9.

15. Sozzi G, Miozzo M, Donghi R, et al. Deletions of $17 p$ and p53 mutations in preneoplastic lesions of the lung. Cancer Res 1992;52:6079-82.

16. Harris CC. Structure and function of the p53 tumor suppressor gene: clues for rational cancer therapeutic strategies. J Natl Cancer Inst 1996;88:1442-55.

17. Reichel MB, Ohgaki H, Petersen I, Kleihues P. p53 mutations in primary human lung tumors and their metastases. Mol Carcinog 1994;9:105-9.

18. Mountain C. A new international staging system for lung cancer. Chest 1986;89:225s-32s.

19. Shimosato Y. Pulmonary neoplasms. In: Sternberg SS, editor. Diagnostic surgical pathology. New York: Raven Press; 1989. p. $785-827$.

20. World Health Organization. Histological typing of lung tumors (WHO), ed. 2. Am J Clin Pathol 1982;77:123-36.

21. Sugio K, Kishimoto Y, Virmani AK, Hung JY, Gazdar AF. K-ras mutations are a relatively late event in the pathogenesis of lung carcinomas. Cancer Res 1994;54:5811-5.

22. Orita M, Suzuki Y, Sekiya T, Hayashi K. Rapid and sensitive detection of point mutations and DNA polymorphisms using the polymerase chain reaction. Genomics 1989;5:874-9.

23. Noguchi M, Maezawa N, Nakanishi Y, Matsuno Y, Shimosato Y, Hirohashi S. Application of the p53 gene mutation 
pattern for differential diagnosis of primary versus metastatic lung carcinomas. Diagn Mol Pathol 1993;2:29-35.

24. Yang H-K, Linnoila RI, Conrad NK, et al. TP53 and ras mutation in metachronous tumors from patients with cancer of the upper aerodigestive tract. Int J Cancer 1995;64:229-33.

25. Mitsudomi T, Oyama T, Kusano T, Osaki T, Nakanishi R, Shirakusa T. Mutations of the p53 gene as a predictor of poor prognosis in patients with non-small cell lung cancer. J Natl Cancer Inst 1993;85:2018-23.

26. Sidransky D, Mikkelsen D, Schwechheimer K, Rosenblum ML, Cavanee W, Vogelstein B. Clonal expansion of p53 mutant cells is associated with brain tumour progression. Nature 1992;355:846-7.
27. Mitsudomi T, Lam S, Shirakusa T, Gazdar A. Detection and sequencing of p53 gene mutations in bronchial biopsy samples in patients with lung cancer. Chest 1993;104:362-5.

28. Slaughter DP, Southwick HW, Smejkai W. "Field cancerization" in oral stratified squamous epithelium: clinical implications of multicentric origin. Cancer 1953;6:693-8.

29. Chung KY, Mukhopadhyay T, Kim J, et al. Discordant p53 gene mutations in primary head and neck cancers and corresponding second primary cancers of the upper aerodigestive tract. Cancer Res 1993;53:1676-83.

30. Horii A, Han H-J, Shimada M, et al. Frequent replication errors at microsatellite loci in tumors of patients with multiple primary cancers. Cancer Res 1994;54:3373-5. 